\title{
The effect of early physiotherapy after an acute ankle sprain
}

Kristin Hultman, Anne Fältström and Ulrika Öberg

The self-archived postprint version of this journal article is available at Linköping University Institutional Repository (DiVA):

http:// urn.kb.se/ resolve?urn=urn:nbn:se:liu:diva- 152672

N.B.: When citing this work, cite the original publication.

This is an electronic version of an article published in:

Hultman, K., Fältström, A., Öberg, U., (2010), The effect of early physiotherapy after an acute ankle sprain, Advances in Physiotherapy, 12(2), 65-73. https:/ / doi.org/ 10.3109/ 14038190903174262

Original publication available at:

https:/ / doi.org/ 10.3109/ 14038190903174262

Copyright: Taylor \& Francis (STM, Behavioural Science and Public Health Titles)

http://www.tandf.co.uk/journals/default.asp 
The effect of early physiotherapy after an acute ankle sprain

\begin{abstract}
Ankle sprain is one of the most common injuries treated in the emergency departments (ED). In clinical practice these injuries are expected to heal by themselves, often without any other treatment than short information about the RICE regime (rest, ice, compression and elevation). Still, remaining symptoms are reported to occur in $30 \%$ of the cases. The aim of this study was to evaluate the effect of early physiotherapy intervention after an acute ankle sprain. Sixty-five patients were recruited from the ED at a general hospital in Sweden (mean age 35 years; 30 women), and allocated into an intervention group with early physiotherapy or a control group. Both groups were evaluated six weeks and three months after their injury. As primary outcome the disease-specific Foot and Ankle Outcome Score (FAOS) was used. The patients also rated their physical activity ability and how satisfied they were with their ankle on a visual analogue scale (VAS). The intervention group made significant improvements compared to the control group at both evaluations measured with FAOS and the VASquestions. These findings indicate that early physiotherapy intervention has a positive effect on patient-focus foot- and ankle function after an acute ankle sprain.
\end{abstract}

Key words: FAOS, outcome, self care, rehabilitation 


\section{Introduction}

Ankle sprain is one of the most common musculoskeletal injuries $(1,2)$. In the UK approximately 5000 ankle sprains occur each day (3), and in Sweden up to 300000 each year (4). The incidence has been estimated at one ankle sprain per 10000 people per day (5). The injury is painful and incapacitating, and in the acute phase weightbearing is difficult to tolerate, for all but the most minor injuries (6). Most ankle sprains are sustained during sport, but with increasing age, other activities, such as stumbling on ground level or falling down stairs, become dominant (7). The costs involved are high, since about a quarter of all injured people are absent from school or work for more than seven days (3). Remaining symptoms, such as chronic complaints of pain, swelling or recurrent sprains, are reported in approximately $30 \%$ of the cases (8-11).

Valderrabano et al has showed that in $13 \%$ of posttraumatic osteoarthritis cases the cause is a ligamentous lesion (12).

In literature and among clinicians, a general agreement is that acute ankle sprains should initially be treated with a non-operative treatment programme (13-16) called functional treatment. This treatment includes application of the RICE principle (rest, ice, compression and elevation) immediately after the injury, a short period of immobilization and protection with tape or bandage, early range of motion exercises followed by early weight-bearing and proprioceptive ankle training (13, 17-19). The ultimate goal is a post-injury return to prior level of function and/or sport (20). In clinical practice, ankle sprains however have long been expected to heal well with little or no rehabilitation and are not routinely referred to physiotherapy departments (6, 21). Changes in today's health care demands physiotherapists to be more accountable for providing appropriate, yet cost-effective treatment (22). The questions therefore remain: Should we be more accurate with follow up and treatment of ankle sprain? Can 
this be made cost-effective by extending the information given at the emergency department (ED) with just a few visits to a physiotherapist? The aim of this study was to evaluate the effect of early physiotherapy intervention after an acute ankle sprain.

\section{Materials and Methods}

Study design and participants

This study was carried out in a physiotherapy unit at a general hospital in Sweden, in collaboration with the ED, from August 2004 to April 2005, 115 patients between 18-65 years visited the ED with an ankle sprain. The patients had to meet the following inclusion and exclusion criteria for entry into the study. The inclusion criteria were: (a) acute ankle sprain, where x-ray or obvious clinical signs showed no fracture (23). Flake fractures $(\leq 2 \mathrm{~mm})$ of the lateral malleolus were included as they are normally treated as soft tissue injuries (24); (b) Age 18-65 years old; (c) reading, writing and understanding the Swedish language. Exclusion criteria were; (a) earlier fracture or surgery of the injured ankle, (b) injuries or diseases in the lower extremities that have caused great functional disabilities like rheumatic diseases and neurological injuries or diseases, (c) ankle sprain in the same ankle during the previous year, that required health care, (d) a visit to another physiotherapist for treatment of the injured ankle.

The study was approved by the Regional Ethical Review Board in Linköping, Sweden (Dnr 13-4).

The patients who fulfilled the criteria for inclusion in the study and accepted to participate were allocated into either an intervention group or a control group by their date of birth (equal or unequal number). All patients were informed verbally and by writing about the study and gave their informed consent to participate. At the ED all 
patients received conventional treatment after the acute ankle sprain. This in general means; an examination of the ankle, usually initial weight-unloading with crutches, elastic wrap, and verbal and/or written information from the attending physician or nurse about mobilization and early weight-bearing. This conventional treatment is given regardless of participation in this study or not, as there is no standardised treatment regime at the ED for this patient group. Conventional treatment can therefore differ from patient to patient. We do not know the extent of the information the patient in this study received at the ED. Neither if the information was in writing or only verbally, nor how the patients complied to the given information.

\section{Intervention}

The patients in the intervention group were contacted by phone and were offered a visit to a physiotherapist as soon as possible after the injury (range 1-14 days, median 4 days), and follow-ups after three weeks, six weeks and three months. The patients in the control group were contacted by letter and phone for visits six weeks and three months after their injury. The intervention group had four visits to the physiotherapist and the control group had two visits. All patients in the study visited the same physiotherapist, who has a specialist competence in sports medicine (AF). The visits for both groups consisted of an examination of the injured ankle, information of the ankle anatomy and function and instructions in home exercises. These exercises were functionally based, allowing the patient to progress according to his or her functional ability. The home exercises consisted of early range of motion training, followed by weight-bearing on the injured ankle, balance- and strength training $(19,25)$. There was no difference in the physiotherapy intervention between the groups. Both groups received the same information and the same exercises, but at different times after the injury depending on 
which of the groups the patient belonged to. The information given at the ED was out of our control.

Standardized exercise programs were used in this study (Table 1). The individual exercises were bases on data from the physiotherapy examination and the patient's physical activity level before the ankle sprain. The exercises were instructed and tested at the physiotherapy unit before continuing as home exercises. All patients in the study were asked to report compliance (frequency of home-exercises and frequency of other physical activity) through a training-diary. The patients were instructed to train according to Thomeé's pain control model (26). This model informs the patients that pain during and after training is accepted. Pain up to 5 on a 10-grade visual analogue scale (VAS) is permitted, if the pain diminish directly after the activity. No manual therapies were used in this study.

\section{Measurements}

Both groups were evaluated six weeks and three months after their injuries, by a blinded physiotherapist (KH), who did not know which group the patient belonged to. The following measurements were used;

Foot and Ankle Outcome Score (FAOS). The disease-specific FAOS was the primary outcome measure. FAOS is a 42-item self-administrated foot- and ankle-specific questionnaire by Roos (27). FAOS has been developed to be used for short- and longterm follow-up studies of foot- and ankle injuries, to assess changes from week to week induced by treatment or over the years. It comprises five subscales: Pain, Symptoms, Activities of Daily Life (ADL), Sports and Recreation Function (Sport/Rec) and footand ankle-related Quality of Life (QOL). A score from 0 to 100 is calculated for each 
subscale; 100 represent the best result. FAOS has been confirmed for validity, reliability and responsiveness (27), FAOS can be downloaded from http://www.koos.nu.

Visual analogue scale. VAS was used to assess the subjects' responses to the question “Compared to normal, how would you rate your physical activity ability today?” by making a cross on a 100-mm line situated between two polar descriptors ('normal, no limitation' and 'severely limited') (28), and the question "How satisfied are you with your ankle?” by making a cross between 'completely satisfied' and 'not satisfied at all'. The reliability and validity of the VAS have been previously addressed (29, 30).

Returning to work. Subjects were asked to judge the rate of heaviness their work implied on a self reporting scale from 0-6 (modified from Steven Edworthy, McCraig Centre for Joint Injury \& Arthritis Research, Calgary, Alberta, Canada) (31) (Table 2). The patients were asked to mark the description that described their working level the best. The scale has not been tested for validity and reliability.

The days off work were counted for those patients who had an employment. The calculation was based on a five-day working week, with the weekends off. Some of the patients were students and some unemployed and they were not included in this calculation.

Other measurements. Range of motion (ROM) of the ankle in dorsi- and plantar flexion was measured with a goniometer (28). Postural control was evaluated in both groups by the test - Standing on One Leg Eyes Closed (SOLEC) (32), and the subject's ability to weight-bear on the injured ankle were evaluated with an activity score containing six weight-bearing activities such as walk, run, single hop and stair hop. The activity score 
has earlier been used by Wilson and Gansneder when examining the variables that best predicted the time from the injury to regaining full physical activity capacity after an acute ankle sprain (28).

\section{Statistical analysis}

The statistical analysis was performed using the Statistical Package for Social Sciences (SPSS), Version 15.0. The underlying data obtained from questionnaires such as FAOS were ordinal, which implied the use of non-parametric statistics. For comparisons between the intervention group and the control group the Mann-Whitney test was used. The level of significance was set to $\mathrm{p}<0.05$.

A power analysis was carried out prior to the study. It was determined that totally 60 patients were needed to detect a clinically significant mean score difference of 10 points in FAOS subscale pain between the groups with $80 \%$ power and at $\mathrm{p}=0.05$.

We are aware that the instrument FAOS contains ordered categorical data. From a statistical/mathematical point of view the proceeding for calculation as described in the user's guide (www.koos.nu) is not fully correct. Because of this reason all data from the instrument FAOS have been double-checked by the Elisabeth Svensson-method (33), which showed the same results of the calculation as described in this article. This arrangement was made to minimize the risk of incorrect conclusions.

\section{Results}

Ninety-five patients fulfilled the criteria for inclusion in the study. Thirty patients (16 patients in the intervention group and 14 patients in the control group) were not included in the study on account of reasons such as the patients were not interested or we could not get in touch with the patients. Sixty-five patients (30 women) remained for 
inclusion (mean age 35, range 18-65 years) (Figure 1). Patients' characteristics are shown in Table 3.

FAOS. At the evaluation six weeks after injury the intervention group had significant improvements compared to the control group in all of FAOS subscales (pain $p=0.001$, symptoms $p=0.018$, ADL $p=0.002$, sport $/$ rec $p=0.008$, QOL $p=0.017)$. At three months the results were the same (pain $p=0.025$, symptoms $p=0.046$, ADL $p=0.003$, sport/rec $p=0.029)$ except for the subscale QOL $(p=0.135)$ (Figure 2).

VAS. In the question "Compared to normal, how would you rate your physical activity ability today?” the intervention group rated themselves significantly better then the control group at the evaluation at six weeks $(p<0.001)$, and three months $(p=0.038)$ after the injury. In the question "How satisfied are you with your ankle?” the intervention group rated themselves significantly better then the control group at both six weeks $(p<0.001)$, and three months $(p=0.008)$ (Figure 3$)$.

Returning to work. There was no significant difference between the two groups in the self-reported working condition before the injury, on the modified Edworthy scale from 0-6 ( $p=0.579)$ (Table 2). When comparing the days of sick leave we found that of those patients that had an employment $(n=50)$, more than a quarter were absent from work for more than seven days $(n=13)$, but no significant difference could be detected $(p=0.768)$ (Table 3).

Other measurements. There was no difference between the groups in ROM, in dorsi- or plantar flexion when comparing the uninjured with the injured ankle at both six weeks and three months after the injury (median range from $0^{\circ}$ to $5^{\circ}$ difference). Neither was 
there significant difference between the groups in postural control measured with SOLEC (injured ankle: six weeks $p=0.134$, three months $p=0.864$, uninjured: six weeks $p=0.609$, three months $p=0.573$ ) or in which task the two groups completed in the weight-bearing activity score (injured ankle: six weeks $p=0.269$, three months $p=$ 0.544, uninjured: six weeks $p=0.517$, three months $p=0.951$ ).

\section{Discussion}

Summary of main findings. This study was designed to determine the patient-focused foot- and ankle function after an acute ankle sprain and to examine if there was a value in receiving extended information about self care and training of the ankle beyond the conventional treatment at the ED. The main results in this study indicate that early physiotherapy intervention had a positive effect on patient-focus foot- and ankle function after an acute ankle sprain. In nearly all parts of the self-evaluating scales (FAOS and VAS) the intervention group had made significant improvements compared to the control group, at the evaluations at six weeks and three months after the injury. First at the evaluation three months after the injury the control group reached the same level of ankle function as the intervention group had reached at the evaluation six weeks after the injury (Figure 2). These results, achieved with minimal physiotherapy input in terms of time and cost, indicate that early extended information and early physiotherapy makes a difference for the recovery after an acute ankle sprain.

Strength and limitations of the study. The general agreement today is that acute ankle sprain should be treated with functional treatment $(13,15,18,19,24,25)$. However, this knowledge is rarely transferred into daily clinical practice, since ankle sprains have long been expected to heal well by themselves with little or no rehabilitation (21). Today at 
heavily burdened ED: s the patients needs of information and instruction after an acute ankle sprain can be hard to prioritize. Chorley et al (34) showed that less than one \% of patients who were discharged from the ED with acute ankle sprain, received instructions including the essential components for optimal management and rehabilitation, and only $16 \%$ of the discharge instructions contained the basic, minimal information to decrease pain and swelling (RICE) (34). Residual lifestyle-limiting symptoms are common in approximately $30 \%$ of all patients six months to seven years after an ankle sprain (8, 9, 11, 35), and reinforces the notion that ankle sprains are not just simple injuries (11), but may be more problematic than generally thought (8). Verhagen et al (35) concludes that “there is no such thing as a simple sprain”.

There is a high risk that many patients do not receive adequate information and rehabilitation after their ankle sprain, and thereby slow down the time before returning to pre-injury level.

We chose to evaluate the control group and the intervention group at six weeks since we at the start of the study believed that the groups would be almost recovered in their injured ankle at six weeks. Thereby we considered it appropriate to evaluate at that time. In clinical studies control groups are usually left without treatment. In this study the control group received intervention at their visits as well, in order to increase their motivation to participate in the study and also from an ethical point of view. In this case we however believe it further strengthens the results in the study.

A few limitations in the present study should be noted. Based on the current study it may be difficult to determine whether it was the extended information or the physiotherapy intervention that was responsible for the observed treatment effect. We believe that it is a combination. The physiotherapist can mediate both extended information and confidence to start weight-bearing and exercises early after the injury, 
to regain function faster. Our focus in this study has been on the information to the patient, and not on how well the patients complied in the exercise program. All patients were asked to report compliance through a training-diary. Most of the patients forgot to hand in this diary and of those who did, the reports were difficult to compare between the patients, since they were differently completed, and therefore difficult to evaluate. It was not practically viable to make baseline measurements at the ED with the measurements used in this study. FAOS, for example isn't developed for evaluation in the acute phase of the injury, since it asks for problems you have had the previous week. Neither is it possible to use severity of the injury as a baseline measurement. Traditionally, lateral sprains of the ankle have been classified into three groups, grade I (mild), II (moderate), or III (severe) $(21,36)$. This grading however is often impossible in the emergency situation, because the pain and swelling prevents full clinical assessment (6) and makes the evaluation difficult and unreliable (13). When checking the patients' journals in this study, no one had been graded in severity at the ED. On the basis of the setup in this study we had to use other measures at baseline, such as incidence of previous sprains and lateral versus medial injuries since the medial is less common (37) and may be considered to be more severe. The allocation between the two groups in comparable baseline measures were rather even and together with the power analysis made in the beginning of the study we consider the groups to be comparable at baseline.

We used date of birth to allocate the patients into either an intervention group or a control group. We are aware that this is not an appropriate method for allocation since it increases the risk of bias in the study.

Our study evaluated the effect of early physiotherapy intervention with focus on conveying confidence to the patient to begin early mobilisation after the acute ankle 
sprain. We did not intend to evaluate the information itself but the recovery of anklefunction. The choice of measurements was based on other intervention-studies for ankle sprains at the time of start of the study. ROM, postural control, functional instability and strength had long been used as variables for evaluation of ankle function $(18,20,38)$. Instruments reporting pain, satisfaction, symptoms and function to assess the effect of treatment interventions from the patients point of view have become more common during the last years (39). Based on the setup, and at the time of start in our study, we believed FAOS to be the best available instrument of choice for measuring patientfocused foot and ankle-function.

The objective variables in this study such as ROM, postural control or weight-bearing activities didn't show significant differences between the two groups. However, it may be possible that even though you have a rather good function in your ankle during controlled forms (for example during the tests), you can’t rely on your ankle during daily activities when for example ascending stairs, or getting in or out of a car, as showed by the self-evaluation scales. Many performance measures are lacking when the aim is to draw an inference about the patient's overall functional status, rather than a specific activity such as hopping (40). Also the variable returning to work didn't show a significant difference between the two groups. Since there was a high number of students and unemployed in the two groups, the number of patients to compare was rather small. The result from this study however might have a clinical value since the intervention group returned to work in mean 1.5 days earlier.

Comparison with existing literature. Several studies $(14,18,41)$ have showed that functional treatment is the treatment of choice after an acute ankle sprain, and reinforce the importance of supervised rehabilitation and physiotherapy (20, 38). Questions about 
the most effective set-up of the intervention remain. To our knowledge no studies with a similar study-design as ours have been made. Van Rijn et al:s study from 2007 is however partly comparable with our study. They failed to demonstrate a clearly superior treatment approach when comparing conventional treatment combined with supervised exercises compared to conventional treatment alone (1). They however stated that the conventional treatment in the Netherlands differs from other countries since conventional treatment in other countries is less extensive, and thereby can influence the results in the study (1). The setup in their conventional treatment-group is however more comparable to our intervention group, but their choice of outcome measures are not. They used subjective recovery (on a 0-10 point scale) and occurrence of re-sprains as primary outcome measures. Subjective recovery was not comparable with outcomes from our study and the occurrence of re-sprains were more than $20 \%$ in both their groups after three months, compared to $3 \%$ in our intervention group and $6 \%$ in our control group.

Implications for future research or clinical practice. Based on the results of this study it would be of interest to further study if a clearly written program containing information about the injury and home-exercises could replace the visits to the physiotherapist, to determine which of either the physiotherapy intervention or the extended information is essential after an acute ankle sprain. It would also be of interest to further study the relationship between early physiotherapy intervention and returning to work after an acute ankle sprain. 


\section{Conclusion}

The findings in this study indicate that early physiotherapy intervention has a positive effect on patient-focus foot- and ankle function after an acute ankle sprain during the first three months after the injury.

\section{References}

1. van Rijn RM, van Os AG, Kleinrensink GJ, Bernsen RM, Verhaar JA, Koes BW, et al. Supervised exercises for adults with acute lateral ankle sprain: a randomised controlled trial. Br J Gen Pract. 2007 Oct;57(543):793-800.

2. van Os AG, Bierma-Zeinstra SM, Verhagen AP, de Bie RA, Luijsterburg PA, Koes BW. Comparison of conventional treatment and supervised rehabilitation for treatment of acute lateral ankle sprains: a systematic review of the literature. J Orthop Sports Phys Ther. 2005 Feb;35(2):95-105.

3. de Bie RA, de Vet HC, van den Wildenberg FA, Lenssen T, Knipschild PG. The prognosis of ankle sprains. Int J Sports Med. 1997 May;18(4):285-9.

4. Leanderson J. Har vi råd att inte behandla fotledsinstabilitet? Svensk Idrottsforskning. 1997;1:19-.

5. Trevino SG, Davis P, Hecht PJ. Management of acute and chronic lateral ligament injuries of the ankle. Orthop Clin North Am. 1994 Jan;25(1):1-16.

6. Cooke MW, Lamb SE, Marsh J, Dale J. A survey of current consultant practice of treatment of severe ankle sprains in emergency departments in the United Kingdom. Emerg Med J. 2003 Nov;20(6):505-7.

7. Holmer P, Sondergaard L, Konradsen L, Nielsen PT, Jorgensen LN. Epidemiology of sprains in the lateral ankle and foot. Foot Ankle Int. 1994 Feb;15(2):72-4.

8. Braun BL. Effects of ankle sprain in a general clinic population 6 to 18 months after medical evaluation. Arch Fam Med. 1999 Mar-Apr;8(2):143-8.

9. Konradsen L, Bech L, Ehrenbjerg M, Nickelsen T. Seven years follow-up after ankle inversion trauma. Scand J Med Sci Sports. 2002 Jun;12(3):129-35.

10. van Rijn RM, van Os AG, Bernsen RM, Luijsterburg PA, Koes BW, Bierma-

Zeinstra SM. What is the clinical course of acute ankle sprains? A systematic literature review. Am J Med. 2008 Apr;121(4):324-31 e6.

11. Anandacoomarasamy A, Barnsley L. Long term outcomes of inversion ankle injuries. Br J Sports Med. 2005 Mar;39(3):e14; discussion e.

12. Valderrabano V, Hintermann B, Horisberger M, Fung TS. Ligamentous posttraumatic ankle osteoarthritis. Am J Sports Med. 2006 Apr;34(4):612-20.

13. Lynch SA, Renstrom PA. Treatment of acute lateral ankle ligament rupture in the athlete. Conservative versus surgical treatment. Sports Med. 1999 Jan;27(1):61-71.

14. Jones $\mathrm{MH}$, Amendola AS. Acute treatment of inversion ankle sprains: immobilization versus functional treatment. Clin Orthop Relat Res. 2007 Feb;455:16972.

15. Struijs P KG. Ankle sprain. BMJ Clin Evid [serial on the Internet]. 2007; 12:1115.

16. Karlsson J, Eriksson BI, Sward L. Early functional treatment for acute ligament injuries of the ankle joint. Scand J Med Sci Sports. 1996 Dec;6(6):341-5. 
17. Ivins D. Acute ankle sprain: an update. Am Fam Physician. 2006 Nov 15;74(10):1714-20.

18. Kannus P, Renstrom P. Treatment for acute tears of the lateral ligaments of the ankle. Operation, cast, or early controlled mobilization. J Bone Joint Surg Am. 1991 Feb;73(2):305-12.

19. Mattacola CG, Dwyer MK. Rehabilitation of the Ankle After Acute Sprain or Chronic Instability. J Athl Train. 2002 Dec;37(4):413-29.

20. Chun DJ, Chow F. Physical therapy rehabilitation of the ankle. Clin Podiatr Med Surg. 2002 Apr;19(2):319-34, vii.

21. Watts BL, Armstrong B. A randomised controlled trial to determine the effectiveness of double Tubigrip in grade 1 and 2 (mild to moderate) ankle sprains. Emerg Med J. 2001 Jan;18(1):46-50.

22. De Carlo MS, Sell KE. The effects of the number and frequency of physical therapy treatments on selected outcomes of treatment in patients with anterior cruciate ligament reconstruction. J Orthop Sports Phys Ther. 1997 Dec;26(6):332-9.

23. Stiell IG, Greenberg GH, McKnight RD, Nair RC, McDowell I, Worthington JR. A study to develop clinical decision rules for the use of radiography in acute ankle injuries. Ann Emerg Med. 1992 Apr;21(4):384-90.

24. ICSI. Health care guideline - ankle sprain [homepage on the Internet]. Minnesotac2001-2006 [cited 2006 april 28]; Available from: http://www.icsi.org/.

25. Zoch C, Fialka-Moser V, Quittan M. Rehabilitation of ligamentous ankle injuries: a review of recent studies. Br J Sports Med. 2003 Aug;37(4):291-5.

26. Thomee R. A comprehensive treatment approach for patellofemoral pain syndrome in young women. Phys Ther. 1997 Dec;77(12):1690-703.

27. Roos EM, Brandsson S, Karlsson J. Validation of the foot and ankle outcome score for ankle ligament reconstruction. Foot Ankle Int. 2001 Oct;22(10):788-94.

28. Wilson RW, Gansneder BM. Measures of functional limitation as predictors of disablement in athletes with acute ankle sprains. J Orthop Sports Phys Ther. 2000 Sep;30(9):528-35.

29. Miller MD, Ferris DG. Measurement of subjective phenomena in primary care research: the Visual Analogue Scale. Fam Pract Res J. 1993 Mar;13(1):15-24.

30. Price DD, McGrath PA, Rafii A, Buckingham B. The validation of visual analogue scales as ratio scale measures for chronic and experimental pain. Pain. 1983 Sep;17(1):45-56.

31. Roos EM, Roos HP, Ryd L, Lohmander LS. Substantial disability 3 months after arthroscopic partial meniscectomy: A prospective study of patient-relevant outcomes. Arthroscopy. 2000 Sep;16(6):619-26.

32. Hansson EE, Mansson NO, Hakansson A. Effects of specific rehabilitation for dizziness among patients in primary health care. A randomized controlled trial. Clin Rehabil. 2004 Aug;18(5):558-65.

33. Svensson E. Construction of a single global scale for multi-item assessments of the same variable. Stat Med. 2001 Dec 30;20(24):3831-46.

34. Chorley JN. Ankle sprain discharge instructions from the emergency department. Pediatr Emerg Care. 2005 Aug;21(8):498-501.

35. Verhagen RA, de Keizer G, van Dijk CN. Long-term follow-up of inversion trauma of the ankle. Arch Orthop Trauma Surg. 1995;114(2):92-6.

36. Cass JR, Morrey BF. Ankle instability: current concepts, diagnosis and treatment. Mayo Clinical Process. 1984;59:165-70.

37. Wolfe MW, Uhl TL, Mattacola CG, McCluskey LC. Management of ankle sprains. Am Fam Physician. 2001 Jan 1;63(1):93-104. 
38. Holme E, Magnusson SP, Becher K, Bieler T, Aagaard P, Kjaer M. The effect of supervised rehabilitation on strength, postural sway, position sense and re-injury risk after acute ankle ligament sprain. Scand J Med Sci Sports. 1999 Apr;9(2):104-9.

39. Martin RL, Irrgang JJ. A survey of self-reported outcome instruments for the foot and ankle. J Orthop Sports Phys Ther. 2007 Feb;37(2):72-84.

40. Alcock GK SP. Validity of the lower extremity functional scale on athletic subjects with ankle sprains. Physioter Can 2002;54:233-40.

41. Kerkhoffs GM, Rowe BH, Assendelft WJ, Kelly KD, Struijs PA, van Dijk CN. Immobilisation for acute ankle sprain. A systematic review. Arch Orthop Trauma Surg. 2001 Sep;121(8):462-71. 


\section{Tables}

Table 1. Standardized exercise programs.

\begin{tabular}{|c|c|c|}
\hline \multicolumn{3}{|c|}{ Standardized exercise programs used in the study ${ }^{a}$} \\
\hline Exercise program 1 & Exercise program 2 & Exercise program 3 \\
\hline $\begin{array}{l}\text { 1. Move your ankle vigorously up } \\
\text { and down. } \\
20 \text { reps each hour } \\
\text { or as often as } \\
\text { possible }\end{array}$ & $\begin{array}{l}\text { 1. Walk forwards } \\
\text { and backwards } \\
\text { on toes and heels. } \\
3 \text { sets of 5-10 } \\
\text { reps. }\end{array}$ & $\begin{array}{l}\text { 1. Cycling. } \\
\text { Warm up } \\
\text { approximately } \\
\text { 5-10 minutes with } \\
\text { optional resistance }\end{array}$ \\
\hline $\begin{array}{l}\text { 2. Nip and sprawl with your toes. } 20 \\
\text { reps each hour or as } \\
\text { often as possible }\end{array}$ & $\begin{array}{l}\text { 2. Walk on } \\
\text { the inside } \\
\text { and outside } \\
\text { of the foot. } \\
3 \text { sets of } 5-10 \text { reps. }\end{array}$ & $\begin{array}{l}\text { 2. Walk widthways in } \\
\text { a stair. } \\
1-3 \text { sets of } 5-15 \text { steps. }\end{array}$ \\
\hline $\begin{array}{l}\text { 3. Draw letters of } \\
\text { the alphabet in the } \\
\text { air. Do the entire } \\
\text { alphabet one time. }\end{array}$ & $\begin{array}{l}\text { 3. Attach an } \\
\text { exercise tubing } \\
\text { around your foot } \\
\text { and pull the foot } \\
\text { toward you and away from you. } \\
3 \text { sets of 5-15 reps }\end{array}$ & $\begin{array}{l}3 . \text { Take-offs. } \\
1-3 \text { sets of } 5-15 \\
\text { reps. }\end{array}$ \\
\hline $\begin{array}{l}\text { 4. Use a towel or a } \\
\text { ball to slide with } \\
\text { your foot forwards } \\
\text { and backwards. } \\
1-3 \text { sets of 5-15 } \\
\text { reps }\end{array}$ & $\begin{array}{l}\text { 4. Attach the } \\
\text { tubing for training } \\
\text { on the inside and } \\
\text { outside of the foot. } \\
3 \text { sets of } 5-15 \text { reps }\end{array}$ & $\begin{array}{l}\text { 4. Jog in an eight. } \\
\text { Switch } \\
\text { direction, } \\
\text { increase the } \\
\text { speed. } \\
\text { 1-3 sets of 5-15 reps. }\end{array}$ \\
\hline $\begin{array}{l}\text { 5. Toe raises on } \\
\text { both feet at the } \\
\text { same time. } \\
\text { Increase the load } \\
\text { by doing them on } \\
\text { one foot. } \\
\text { 1-3 sets of } 5-15 \text { reps. }\end{array}$ & $\begin{array}{l}\text { 5. Stand on a } \\
\text { step. Do toe } \\
\text { raises on both } \\
\text { feet. Increase the } \\
\text { load by doing } \\
\text { them on one foot. } \\
1-3 \text { sets of } 5-15 \text { reps. }\end{array}$ & $\begin{array}{l}\text { 5. Skate jumps } \\
\text { from side to side. } \\
1-3 \text { sets of } 5-15 \\
\text { reps. }\end{array}$ \\
\hline $\begin{array}{l}\text { 6. Stand on one leg. } \\
\text { Stand for } 30-60 \\
\text { seconds. }\end{array}$ & $\begin{array}{l}\text { 6. Stand on one leg. Increase the } \\
\text { degree of difficulty } \\
\text { by closing your } \\
\text { eyes. Use if } \\
\text { possible a balance } \\
\text { board. Stand for } \\
\text { 30-60 seconds. }\end{array}$ & $\begin{array}{l}\text { 6. Start from the middle. Jump with } \\
\text { two feet together in } \\
\text { all directions. } \\
\text { Increase by jump } \\
\text { only on the injured } \\
\text { foot. } \\
\text { 1-3 sets of 5-15 reps. }\end{array}$ \\
\hline $\begin{array}{l}\text { 7. Stretch your calf muscles with the } \\
\text { assistance } \\
\text { of a wall. } \\
\text { Do it both } \\
\text { with your } \\
\text { back leg } \\
\text { straight and bent. Stretch } 2 \text { sets of } \\
\text { 20-30 seconds. }\end{array}$ & $\begin{array}{l}\text { 7. Stretch your calf muscles with the } \\
\text { assistance } \\
\text { of a wall. } \\
\text { Do it both } \\
\text { with your } \\
\text { back leg } \\
\text { straight and bent. Stretch } 2 \text { sets of } \\
\text { 20-30 seconds. }\end{array}$ & $\begin{array}{l}\text { 7. Stretch your calf muscles with the } \\
\text { assistance } \\
\text { of a wall. } \\
\text { Do it both } \\
\text { with your } \\
\text { back leg } \\
\text { straight and bent. Stretch } 2 \text { sets of } \\
\text { 20-30 seconds. }\end{array}$ \\
\hline
\end{tabular}

${ }^{\text {a }}$ Frequencies, intensity and when the different exercise programs were introduced are reported generally

in this table. The exercises were increased individually. Exercises were performed 2-3 times a day, unless

otherwise stated. $\quad *$ The pictures are from Mobilus Digital Rehab AB 
Table 2. Description of self-reported working condition and number of patients

reporting different working conditions.

\begin{tabular}{llll} 
& Self-reported working condition & & \\
\hline & Which description describes your current work condition the best? & $\begin{array}{l}\text { Intervention } \\
\text { group }(n=33)\end{array}$ & $\begin{array}{l}\text { Control } \\
\text { group }(n=32)\end{array}$ \\
& Please mark one alternative & $n=4$ & $n=6$ \\
\hline $\mathbf{6}$ & Heavy work (lumber jack, fire fighter, construction worker, etc) & $n=5$ & $n=4$ \\
$\mathbf{5}$ & Moderately heavy work (truck driver, scrubbing floors, etc) & $n=6$ & $n=5$ \\
$\mathbf{4}$ & Moderate work (nurse, preschool teacher, housework with kids, etc) & $n=3$ & $n=10$ \\
$\mathbf{3}$ & Light work (hairdresser, sales person, etc) & $n=6$ & $n=1$ \\
$\mathbf{2}$ & Sedentary work (secretary, desk work, student, etc) & $n=6$ & $n=0$ \\
$\mathbf{1}$ & Do not work for reasons other than my foot & $n=0$ & \\
$\mathbf{0}$ & Sick-listed or disability pension because of my foot & & \\
\hline
\end{tabular}

Table 3. Patients' characteristics. If not any other information is given, means and standard deviation (SD) are reported, .

Patients' characteristics

\begin{tabular}{|c|c|c|}
\hline & $\begin{array}{l}\text { Intervention group } \\
(n=33)\end{array}$ & $\begin{array}{l}\text { Control group } \\
(n=32)\end{array}$ \\
\hline Gender male/female $(n)$ & $16 / 17$ & $19 / 13$ \\
\hline Age (years) & 35 (13.9) & $36(14.3)$ \\
\hline Length $(\mathrm{cm})$ & $172(8.5)$ & $174(7.7)$ \\
\hline Weight (kg) & $72.3(8.3)$ & $75.6(8.8)$ \\
\hline Shoe size & $40(2.5)$ & $41(2.2)$ \\
\hline Injured foot right/left $(n)$ & $17 / 16$ & $14 / 18$ \\
\hline Lateral/medial injury $(n)$ & $30 / 3$ & $31 / 1$ \\
\hline Dominant foot right/left $(n)$ & $29 / 4$ & $27 / 5$ \\
\hline Previous ankle sprain injured/uninjured ankle ${ }^{\mathrm{a}}(n)$ & $16 / 10$ & $13 / 14$ \\
\hline Re-sprain during the study ${ }^{\mathrm{b}}(n)$ & $1(3 \%)$ & $2(6 \%)$ \\
\hline \multicolumn{3}{|l|}{ Type of activity at the injury: $(n)$} \\
\hline - work activity & 2 & 4 \\
\hline - everyday activity & 13 & 17 \\
\hline - sport/recreational activity & 18 & 11 \\
\hline The time between injury and seeking the ED & $\begin{array}{l}\text { Median 0, } \\
\text { (range 0-6) }\end{array}$ & $\begin{array}{l}\text { Median 0, } \\
\text { (range 0-13) }\end{array}$ \\
\hline Days before returning to work & $\begin{array}{l}4.6 \quad(n=24) \\
\text { (SD 6.1, range } 0-25)\end{array}$ & $\begin{array}{l}6.1 \quad(n=26) \\
\text { (SD 7.4, range } 0-27)\end{array}$ \\
\hline
\end{tabular}

\footnotetext{
${ }^{a}$ The same patient may have reported both injured and uninjured ankle.

${ }^{\mathrm{b}}$ Did not require any other health care than what was in the study.
} 


\section{Figures}

Figure 1. Description of excluded patients and drop-outs from the study.

Figure 2. Foot and Ankle Outcome Score (FAOS), median are reported.

Figure 3. Self-reported satisfaction and self-reported physical activity ability differences between groups. The number zero is described as 'completely satisfied/normal, no limitation’. 


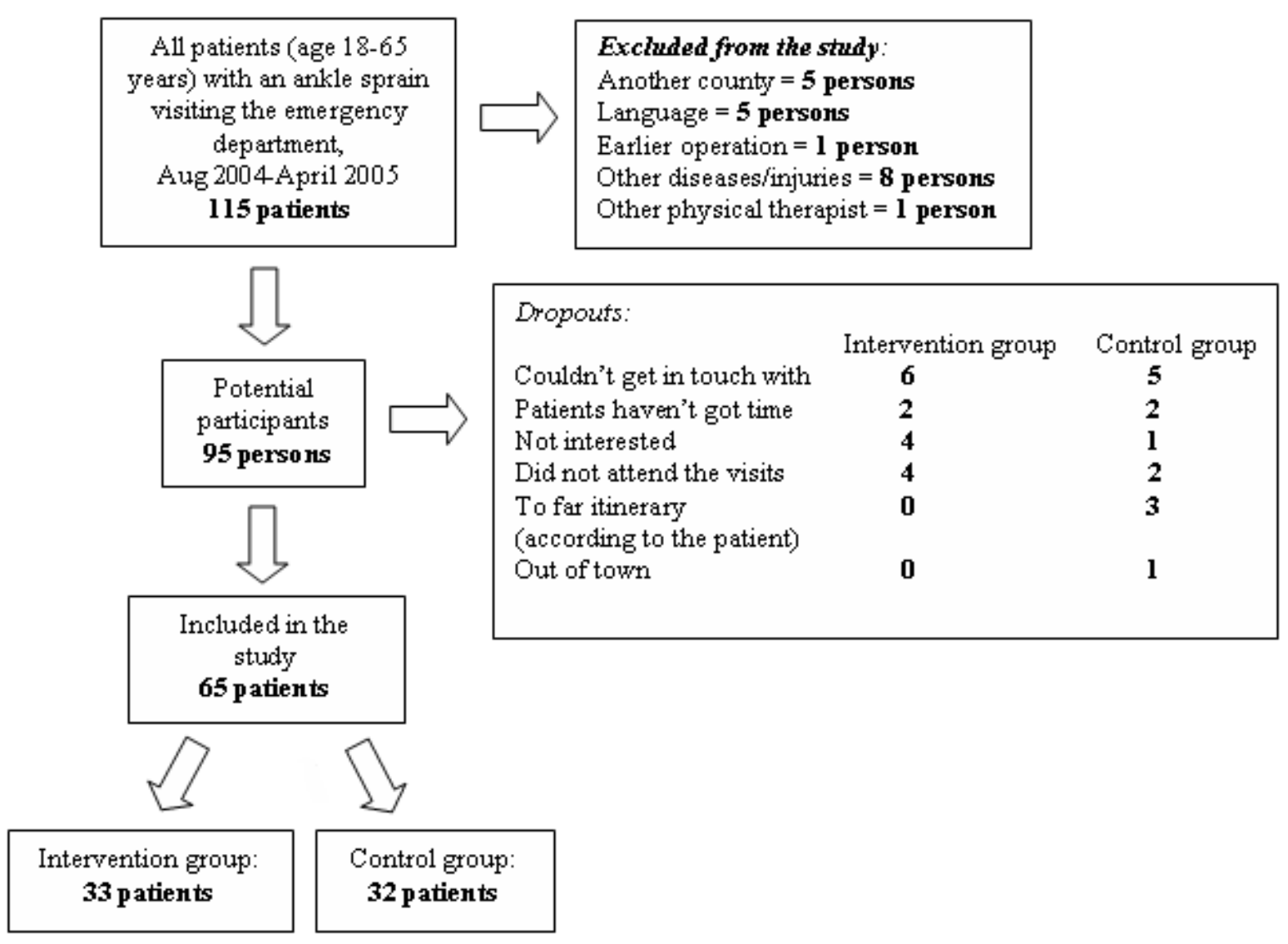

Figure 1.Description of excluded patients and drop-outs from the study. 


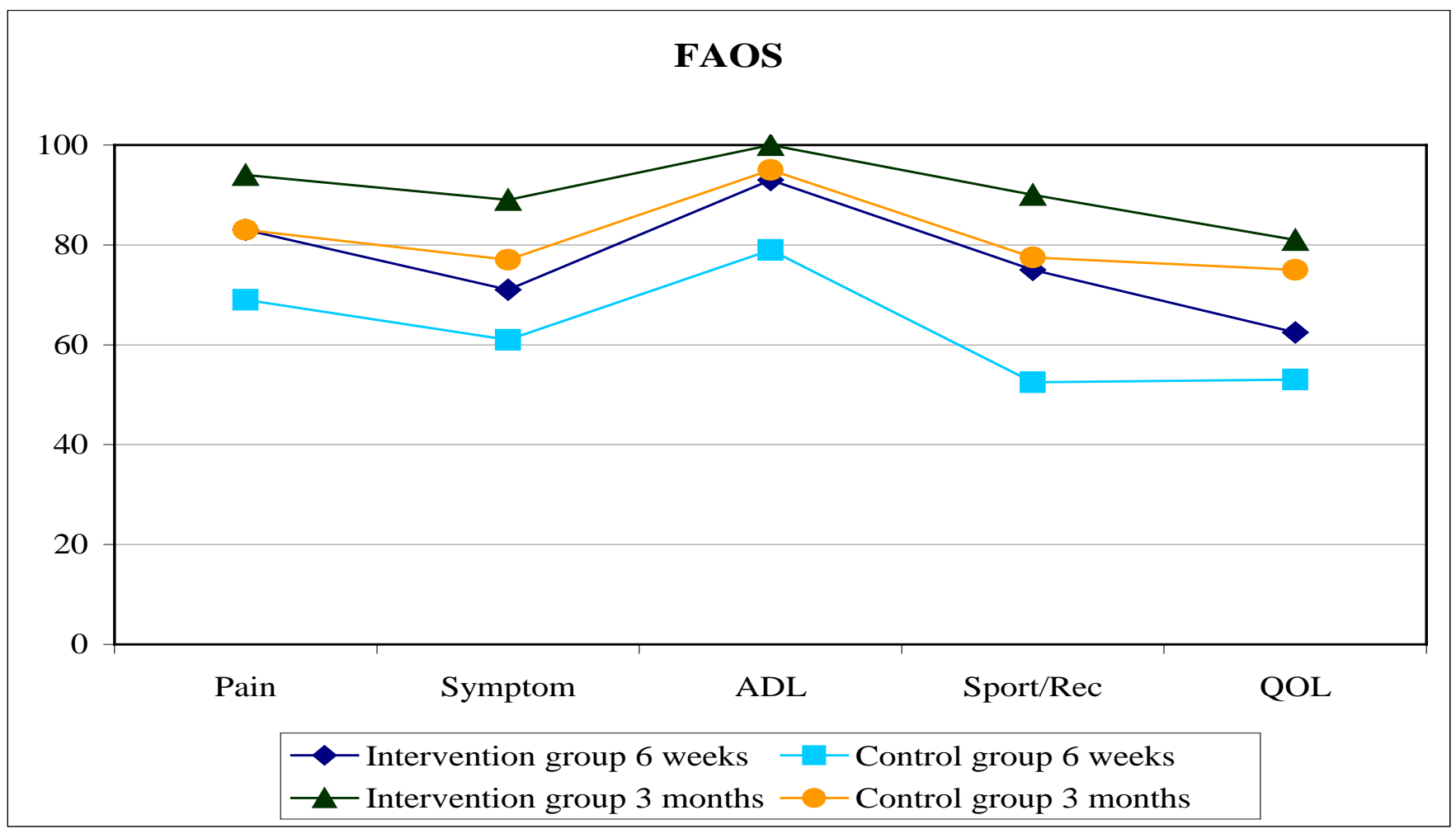

Figure 2. Foot and Ankle Outcome Score (FAOS), median are reported. 


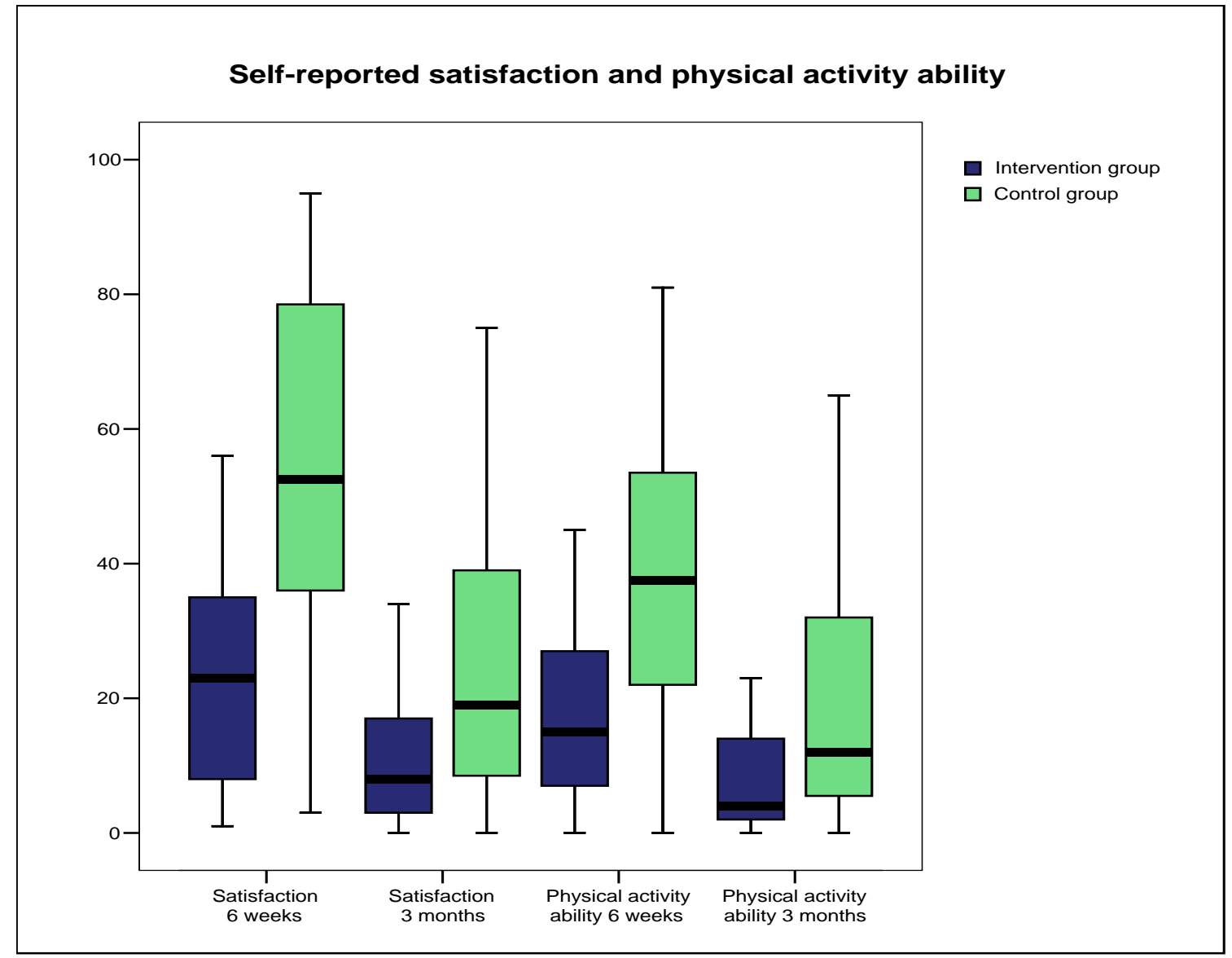

Figure 3. Self-reported satisfaction and self-reported physical activity ability - differences between groups. The number zero is described as ‘completely satisfied/normal, no limitation'. 